\title{
Rapid HPLC method and sample extraction procedures for measuring 25-hydroxyvitamin D3 concentrations in human breast milk
}

\author{
Sawsan Mohammed Ali Hadi*, Dr. Alaa Shaalan Hussien, Azhar Abdul Jabber \\ Nutrition research institute/Baghdad/Iraq \\ *Corresponding author E-mail: sawsanmo@yahoo.com
}

\begin{abstract}
Background; Human breast milk is the milk produced by the breasts (or mammary glands) of a human female for her infant offspring. Milk is the primary source of nutrition for newborns before they are able to eat and digest other foods. Vitamin D describes a group of fat-soluble steroids. Vitamins D2 and D3 can be converted to the active steroid hormone in the human body. The active form of vitamin $\mathrm{D}$ is hydroxylated in two places. The most accurate measurement of vitamin D levels in the body is a blood test that detects the levels of circulating 25-hydroxylated vitamin D.
\end{abstract}

Aims of the study; the purpose of the present study was to develop a protocol for the extraction of cholecalciferol from human breast milk for analysis by HPLC using retinyl acetate as internal standards.

Methods: The HPLC proposed enables successful separation and quantitation of Vitamin D3 (cholecalciferol) and their respective internal standards (retinyl acetate) in less than 10 minutes; RP- C18 column (100 x 4.6 mm I.D.; particle size, 5 micron) at a flow-rate of $1 \mathrm{ml} / \mathrm{min}$, the mobile phase was methanol. The eluate was monitored with a photodiodearray detector with wavelengths $265 \mathrm{~nm}$.

Results: No interference was found from other fat soluble vitamins (vitamin A) that are commonly presents with vitamin D. Reproducibility studies carried out with pooled breast milk showed a within day and between day precision of the analysis did not exceed $2.6 \%$ and $4 \%$ respectively for cholecalciferol. The detection limits were $2.8 \mathrm{ng} / \mathrm{ml}$, the linearity of the standard was excellent (r2 > 0.999), over the concentration range of $0-100 \mathrm{ng} / \mathrm{ml}$.

Conclusions: This method separates fat-soluble vitamins in human breast milk, including cholecalciferol using retinyl acetate as internal standards. HPLC method is a rapid determination and quantification of vitamins D in human breast milk, time-consuming steps and has been shown to be sensitive, and reliable.

Keywords: Breast milk, Cholecalciferol, HPLC, Retinyl acetate, Vitamin D.

\section{Introduction}

The most important physiological functions of vitamin D are the stimulation of the Intestinal resorption of Ca2+ and phosphate and their incorporation in the bon. While breastfeeding is the recommended method of infant feeding and provides infants with necessary nutrients and immune factors, most breastfed infants are able to synthesize additional vitamin D through routine sunlight exposure $(1,2)$.

A number of factors decrease the amount of vitamin D ,These factors include; Living at high latitudes (closer to the Polar Regions), particularly during winter months, Air quality conditions: high levels of air pollution, Weather conditions: dense cloud covering, the degree to which clothing covers the skin, Skin pigmentation: darker skin types $(3,4,5)$.

D-vitamins or calciferols arise from provitamins by the UV radiation of sunlight, In the skin formed Vitamin D3 is bound to a vitamin D binding-protein in the plasma, transported in to the liver and hydroxylated in position 25 to form 25-OH vitamin D3. Another Hydroxylation is performed in the kidney to yield 1, $25(\mathrm{OH}) 2$ vitamin D3 .It is proofed that 1, $25(\mathrm{OH}) 2$ vitamin D3 is the metabolic Most active form of vitamin D. Nevertheless, more than 95\% of 25-OH vitamin D is $25-\mathrm{OH}$ vitamin D3 $(6,7,8)$. 
Vitamin D levels should be monitored and contained within acceptable limits: 40-60 ng/mL or 100-150 nmol/L of 25 $(\mathrm{OH})$ Vitamin D. (Conversion ratio: $1 \mathrm{ng} / \mathrm{mL}$ equal to $2.5 \mathrm{nmol} / \mathrm{L})(9,10)$.

A lack of vitamin D leads in growing humans to rachitis, hypocalcaemia, and secondary hyper parathyroidism, in adults to osteomalasia.

HPLC-application for 25-OH vitamin D3 makes it possible to determine the vitamin in an easy, fast and precise method $(11,12)$.

Because there is a need for a fast reverse-phase high pressure liquid chromatography (HPLC) method than the methods currently available. We developed an HPLC method designed to be easy to use, sensitive, and rapid with simple sample preparation. Separation and quantification and compared several extraction methods for vitamin D3 in human breast milk.

\section{Expected values}

\section{Normal ranges for 25-OH-Vitamin $\mathrm{D}_{3}$}

$1 \mathrm{ng} / \mathrm{ml}=2.5 \mathrm{nmol} / \mathrm{l}$

$1 \mathrm{nmol} / \mathrm{l}=0.4 \mathrm{ng} / \mathrm{ml}$

\section{Information from ASBMR 2006}

Deficiency (seriously deficient) $<12 \mathrm{ng} / \mathrm{ml}$ resp. $<30 \mathrm{nmol} / \mathrm{l}$

Insufficiency (deficient) 12 - $30 \mathrm{ng} / \mathrm{ml}$ resp. $30-75 \mathrm{nmol} / \mathrm{l}$

Sufficiency (adequately supplied) $>30 \mathrm{ng} / \mathrm{ml} \mathrm{resp.}>75 \mathrm{nmol} / \mathrm{l}$

Society of Osteology SACHSEN E. V.

http://osteologie-sachsen.de/aktuelles_vitamin_d.html $(12,13,14)$

\section{Subjects and methods}

\subsection{Milk sampling}

Milk samples were collected from mothers' $5 \mathrm{~mL}$, Whole breast milk aliquots were prepared by gentle swirling of the sample using a vortex mixer before pipetting the whole milk into 2-mL aliquots. Milk aliquots were frozen and stored at $-70^{\circ} \mathrm{C}$

Long-term storage. Exposure of the samples to high temperature and bright light were avoided and the samples were analyzed as soon as possible.

\subsection{Sample preparation}

Breast milk vitamin D3 was measured in breast milk using HPLC. Samples were saponified in NAOH with gentle rotation for $2 \mathrm{~min}$. Samples were extracted with hexane and dried under nitrogen. Once dried, the extracts were resuspended in methanol.

\subsection{Chromatographic settings}

Column dimension: $100 \mathrm{~mm}$ x $4.6 \mathrm{~mm}$

Flow rate: $0.5 \mathrm{ml} / \mathrm{min}$

UV-detection: $265 \mathrm{~nm}$

Injection volume: $20 \mu \mathrm{l}$

Running time: $10 \mathrm{~min}$

Temperature: $30{ }^{\circ} \mathrm{C}$ 


\section{Results}

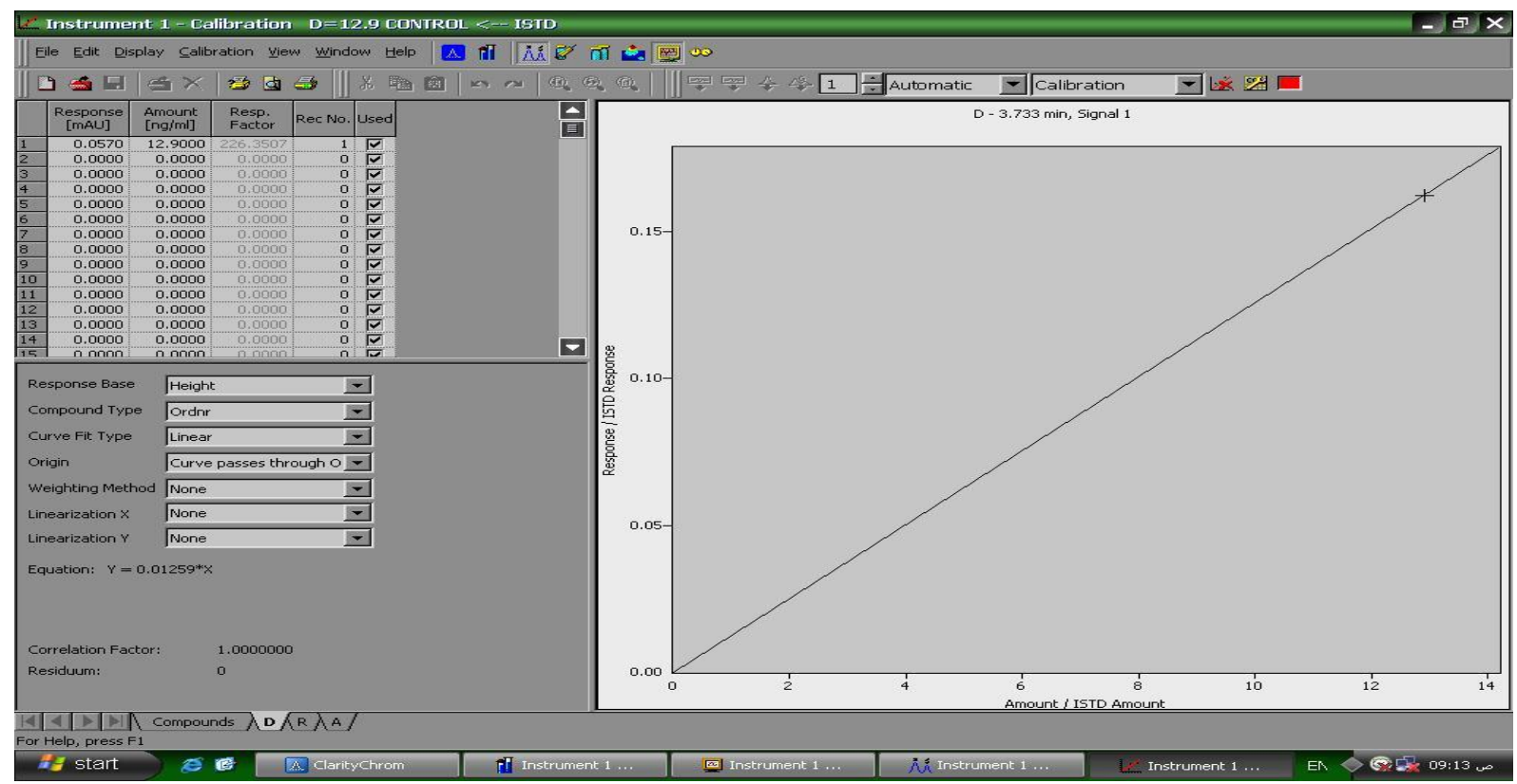

Fig. 1: Typical chromatograms of calibrators, Linearity fit, Concentration (0-100) ng/ml, r (0.999)

\subsection{Typical chromatogram}

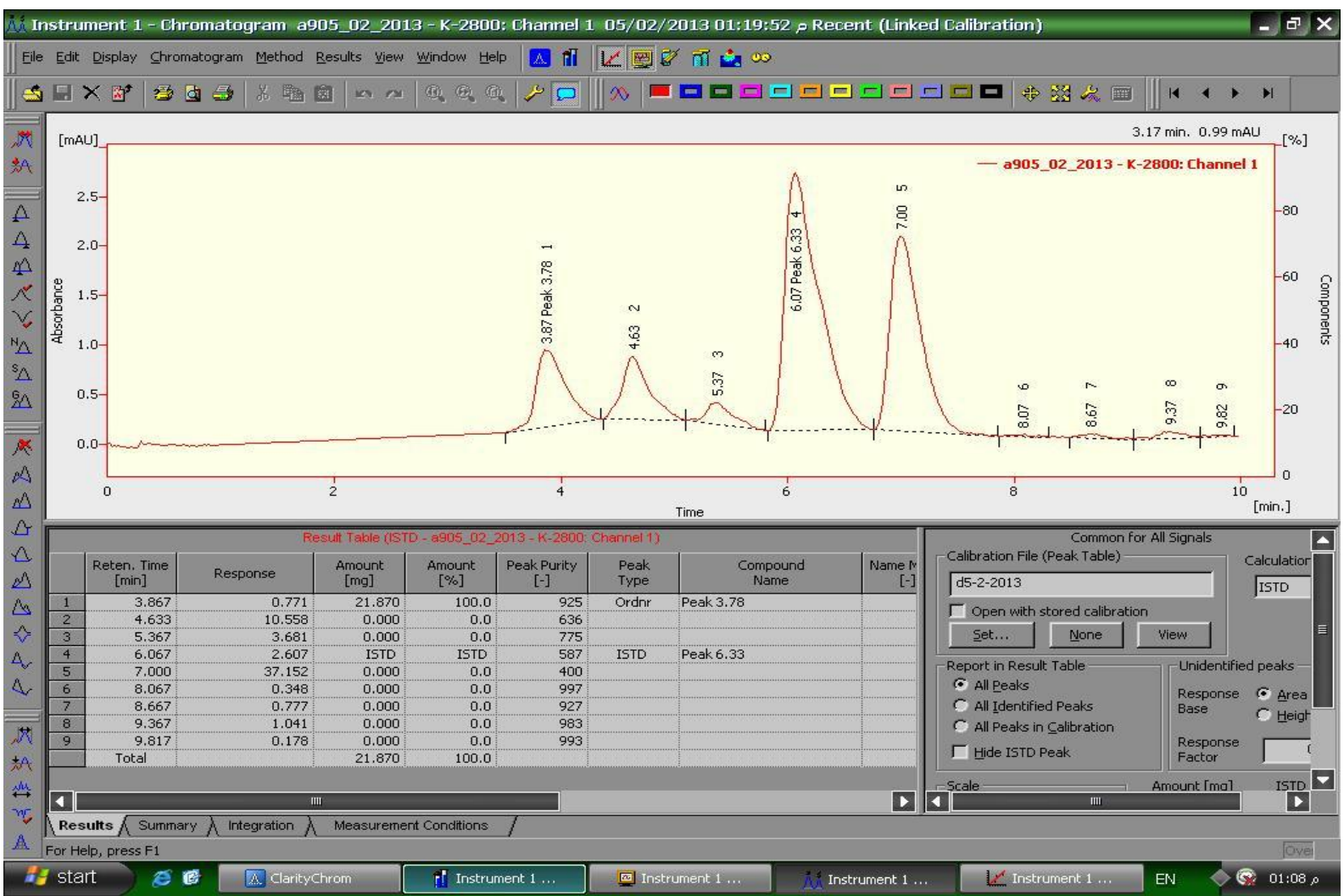

Fig. 2: Chromatogram of human breast milk analyzed by HPLC, breast milk $25(\mathrm{OH}) \mathrm{D} 3$ had a retention time of 3.7min minutes and $6.2 \mathrm{~min}$ minutes for the internal standard 


\section{Method validation}

\subsection{Precision and reproducibility}

Intra-Assay CV: $2.6 \%(20.5 \mathrm{ng} / \mathrm{ml})(\mathrm{n}=6)$

Inter-Assay CV: $4.0 \%(20.1 \mathrm{ng} / \mathrm{ml})(\mathrm{n}=6)$

\subsection{Linearity}

Calibration Curve was prepared by plotting vit.D3 concentrations (ng/ml) versus the high ratio of vit D3 to I.S (retinyl acetate). Each of these standard solutions was injected twice onto the HPLC-column and the peak height ratios were calculated. Linearity of the calibration curve was excellent $(\mathrm{r} 2>0.999)$ for the concentration Range $0-100 \mathrm{ng} / \mathrm{ml}$.

\subsection{Detection limit}

$2.8 \mathrm{ng} / \mathrm{ml}$

\subsection{Specificity test}

The possible interference with the retention times of the vitamins under investigation was evaluated for the vitamins most frequently present, using the same HPLC conditions. No interferences were observed as shown in figure 2. In all experiments the mobile phase was used as the dissolving solvent,. Analyses were performed induplicate.

\section{Discussion}

There is a need for a fast reverse-phase high pressure liquid chromatography (HPLC) method than the methods currently available. Efficient extraction procedures for biological samples are valuable to save time, materials, and cost. We developed an HPLC method and compared several extraction methods for vitamin D3 in human breast milk. The method uses aknauer system equipped with c18 column $(4.6 \times 100 \mathrm{~mm} 5 \mu \mathrm{m})$. Mobile phase of methanol was run at $0.5 \mathrm{~mL} \mathrm{~min}^{-1}$, and run times were complete in approximately $10 \mathrm{~min}$. This rapid method uses little solvent and provides excellent results in the analysis of these fat-soluble nutrients. But in previous study the method for determination of vitamin D3 in milk was established by high-performance liquid chromatography (HPLC) using reversed-phase and straight-phase columns(15).. $25.0 \mathrm{ml}$ of a sample of milk was taken and the lipid was extracted with a solvent mixture of petroleum ether and ethyl ether (1:1). The extracted lipid was subjected to the first preparative HPLC using a Nucleosil C18 column with acetonitrile-methanol (1:1) as the mobile phase, and a fraction containing vitamin D3 was isolated. The fraction was subsequently subjected to the second analytical HPLC using SIL column (straight-phase type) with $0.4 \%$ isopropanol in n-hexane as the mobile phase. Vitamin D3 was assayed by estimating the peak height on the chromatogram.

\section{Conclusion}

We developed a rapid, simple, and very selective HPLC method for the determination of 25(OH) D3 in human breast milk. Using simple HPLC with diod-arry detection. This method provides excellent sensitivity, precision, and accuracy.

\section{References}

[1] Bruce W Hollis and Carol L Wagner. American Journal of Clinical Nutrition Assessment 79 (2004) 717-726.

[2] "WHO | Exclusive breastfeeding". Who.int. 2011-01-15. Retrieved 2011-10-26.

[3] Chung M, Balk, EM, et al. "Vitamin D and calcium: a systematic review of health outcomes". Evidence report/technology assessment, 183 (2009) 1-420.

[4] Aguiar, H.; Silva, A. I.Acta medica portuguesa. "Breastfeeding The importance of intervening"24 (2011)889-896.

[5] Salone, L. R.; Vann Jr, W. F.; Dee, D. L. Breastfeeding; An overview of oral and general health benefits, Journal of the American Dental Association 144 (2013) 143-151. 
[6] Human serum 25-hydroxycholecalciferol response to extended oral dosing with cholecalciferol. Am J Clin Nutr, 77(2003)204-10.

[7] Am J Clin Nutr. Efficacy, 73(2001)288-94

[8] Canfield L, Giuliano A, Neilson E, Yap H, Beta-Carotene in breast milk and serum is increased after a single beta- carotene dose, Am J Clin Nutr, 66 (1997)52-61.

[9] Strobel M, Heinrich F, Biesalski HK, Improved method for rapid determination of vitamin A in small samples of breast milk by highperformance liquid chromatography, J Chromatograph, 898 (2000)179-183.

[10] Schweigert FL, Hurtienne A, Bathe K, Improved extraction procedures for carotenoids in human milk, Int J Vitamin Nutr, 70 (2000)79-83.

[11] Macias C, Schweigert FJ, Changes in the concentration of carotenoids, vitamin A, alpha-tocopherol and total lipids in human milk throughout early lactation, Ann Nutr Metab, 45 (2001) 82-85.

[12] Visser M, Deeg DJ, Puts MT, Seidell JC, Lips P.Am, Low serum concentrations of 25-hydroxyvitamin D in older persons and the risk of nursing home admission, J Clin Nutr. 84 (2006) 616-22.

[13] Grant WB, HolickMF.Benefits and requirements of vitamin D for optimal health: a review. Altern Med Rev. 10 (2005) 94-111.

[14] Wicherts IS, van Schoor NM, Boeke AJ, et al. Lips P Vitamin D status predicts physical performance and its decline in older persons, J Clin Endocrinol Metab, 92 (2007) 2058-65.

[15] Tanumihardjo, S. A. \& Penniston, K. L, Simplified methodology to determine breast milk retinol concentrations, J. Lipid Res, 43 (2002) 350355. 